\title{
The Study of Affect Factor on Bearing Grind Coefficient Contained Metal Link Burned
}

\author{
Zhanjun LIU \\ Faculty of Aerospace Engineering \\ Shenyang Aerospace University \\ Shenyang, China \\ e-mail: 1zjlzjh@163.com
}

\begin{abstract}
According to various problem of oil contained bearing of metal link burned, it is done as relation study of grind coefficient and oil leak, temperature rise and load pressure. The result is given that oil leak is more serious in the condition of higher pressure and lower speed, and grind coefficient is risen quickly; even if oil contained bearing surpass key point, grind coefficient is risen slowly; load pressure is moved to lower with the speed increasing; the grind coefficient is calculated by the formula of conventional bearing.
\end{abstract}

Keywords-metal link burned; oil contained bearing; grind coefficient; lubricate; leak

\section{INTRODUCTION}

Oil bearing generally contains volume fraction of porosity, the pore is containing leaching with lubricating oil. In the process of rotation, due to pump role, lubricating oil is drawn into the clearance between the bearing inside diameter and shaft, to supply the site of friction. According to the function of the sliding bearing, lubricating oil can make a floating on the shaft of the role, this is the same as conventional bearing situation completely. However, compared with the conventional bearing, sintering oil bearing has the following features [1] [4].

Due to the bearing only on the lube oil inside the pore, so oil is insufficient, in the upper bearing inside, diameter clearance would be easy to form a large empty. The lubrication oil may be also through the pore and porous bearing inner leak in the clearance, so at the bottom of the bearing, inside diameter of friction parts have to produce oil pressure to reduce, the tendency of oil film is thinning, leading to even under a lighter, load can also occur in the region of the lubrication of boundary, lubrication is solid contact friction phenomenon.

For oil bearing model, the porosity change of bearing material is under the condition of low pressure and high load operation situation, which first considers connected porosity of $20 \%$ volume fraction medium, when $C=0.001 \mathrm{~cm}$ clearance, clearance oil can exist within the maximum is about $0.2 \%$ volume fraction between shaft and bearing inside diameter of the lubricating, so it is not hard to understand the situation. Secondly, because friction parts of the oil film will be porous bearings in the body due to oil leakage, thus it is thinning or even damage. The tendency become serious with the increase of bearing porosity and the increase of load pressure, the lubrication state is by the fluid lubrication gradually transition to a boundary lubrication and solid contact friction. It summarizes the oil bearing friction coefficient.

\section{THE STUDY ON RELATIONSHIP BETWEEN THE OIL \\ BEARING FRICTION COEFFICIENT AND OIL LEAKAGE}

Starting with connected porosity is about $20 \%$ volume fraction, the effective permeability is about $10 * 10-15 \mathrm{~m} 2$ of oil bearing, under the condition of low pressure, it is high speed, very little oil leak, the oil film is not very thin, so it is mainly dominated by fluid lubrication. In such a low voltage, high speed lubricated bearing and geomagnetic oil supply, under the condition of oil bearing and fluid, compared to conventional bearing, it is smaller friction coefficient[5]. This is because the generated is in the upper portion of the bearing, diameter of the air inside the cavity is formed in the course of lubricating oil bubble, so that the apparent is viscosity of lubricating oil decrease.

Under the condition of high pressure, low speed and oil leakage phenomenon are serious, the oil film thinning is added in the region of the fluid lubrication boundary and solid contact friction, the friction coefficient is rising sharply. The critical point of figure is in the phenomenon. The critical point is compared with the conventional bearing point, it prefers to low voltage, high speed side. This is because conventional bearing of lubricating oil leakage occurs only on both ends of the bearing, and oil bearing will occur through the porosity of the porous body leak, except at both ends of lubricating. The following investigation porosity connected is about $30 \%$ volume fraction, the effective permeability is about oil-retaining bearing, porosity connected is 1.5 times that of oil bearing, oil content is 1.5 times. However, lubricating oil leakage is related to the effective permeability, namely oil bearing II, lubricating oil leakage is an order of magnitude, it is higher than oil bearing. That is to say, oil bearing II keeps the oil film thickness, and the lubrication performance is more difficult, so its critical point is rather low voltage and high speed side.

However, because the two kinds of oil bearing lubricating were found in the pore of bearing the body, so the state of completely stops the oil supply, even more than the critical point, it is compared with the conventional bearing, critical point of the friction coefficient is rising also quite gentle, not prone to burn phenomenon[6]. 


\section{THE COEFFICIENT OF FRICTION BETWEEN THE LOAD PRESSURE AND TEMPERATURE RISE}

It is connected porosity is about $20 \%$ volume fraction of oil bearing, and it is connected porosity about $30 \%$ volume fraction of oil bearing, friction coefficient of load pressure curve is the relationship between the load stress and temperature rising, in order to compare, it is also credited to the experimental data, and which is with a dotted line to draw the fluid lubrication bearings, and geomagnetic oil supply is only at the beginning of the corresponding curve of oil supply of conventional bearings[7]. When the load is less than $0.6 \mathrm{MPa}$, whether oil bearing and fluid lubricated bearing is almost unanimously to geomagnetic oil supply of conventional bearing. When the load increases to $0.6 \mathrm{MPa}$ above, it is connected to porosity high oil bearing, to start increases with temperature rise and friction coefficient.

When the load increases more than 1.0 MPa, porosity is connected lower oil bearing, which also increases with temperature and friction coefficient. The friction coefficient is the temperature rise of the value of the increase of load pressure as the speed increases, when moving to the low voltage side, high speed is on the friction of the oil film, keeping is unfavorable. These increase point and oil bearing is correspond to the critical point of oil bearing .

\section{THE FRICTION COEFFICIENT OF OIL BEARING}

The running characteristics of oil bearing is in geomagnetic between oil supply and the beginning only in the conventional bearing, and which closes to the conventional bearing side of the geomagnetic oil supply. When oil bearing material increases permeability, friction parts of the oil film formation is not fully, the oil-retaining bearing performance will close only in early oil supply of conventional bearings. Oil-retaining bearing, however, is to use its pore containing lubricating oil for lubrication, so it won't play like a fluid lubricated bearing or geomagnetic conventional oil bearing operation features, but it is also hard to like the conventional bearing only in the initial oil supply, soon it is arrived in the dry state of lubricating oil, therefore it is not easy to happen shaft and bearing the phenomenon of burning [8]. In other words, oil bearing can be regarded as the oil pressure of the slip plane with the easy leakage, on the friction of fluid lubrication, add lubrication is boundary lubrication and solid contact is form mixed friction state of geomagnetic conventional oil bearing. So oil bearing can be used for calculation of the coefficient of friction of the conventional bearing, calculation formula is of the coefficient of friction.

$$
\mathrm{V}=\frac{1}{2} \mu_{H_{p}}-\alpha\left(\mu_{s}-\mu_{B}\right)
$$

To confirm oil bearing calculation formula of the friction coefficient, it is made by the connected porosity of $20 \%$, $25 \%, 30 \%, 40 \%, 50 \%$ and $60 \%$ in the bronze oil bearing test, Determination of the permeability is after immersion oil
SAE30, then with bronze bearing usually determine the coefficient of friction.

The following expression:

$$
\begin{gathered}
\frac{p_{0}}{p}=\exp \left(V^{-m} \phi^{n}\right)=\exp \left(V^{-1.01}\right) \\
\mu_{B S}=(1-\alpha) \mu_{B}+\alpha \mu_{s} \\
\mu_{s}=\frac{\tau_{s}}{p_{m}}
\end{gathered}
$$

Determination of the coefficient of friction is the fluid lubrication friction coefficient rate, it mainly depends on the distribution of the load pressure and permeability, speed changes is between 1 to 0 . Under the condition of pressure and velocity of the load, porosity connected is about $20 \%$ volume fraction, the permeability is about sintered bronze department, oil bearing changes is between $1 \sim 0.97$. When the load pressure $\mathrm{p}=1.6 \mathrm{MPa}$, speed $\mathrm{v}=2 \mathrm{~m} / \mathrm{s}$. At this point, type (3) is the friction of the lower bearing area[9].

A variety of operation characteristics is bearing test results. As seen, compared with geomagnetic conventional oil bearing, sintering oil bearing is in high load side, the friction coefficient increases with temperature rise. This is because the oil is on the surface of the sliding bearing, lubricating oil will leak through the pore, so compared with the conventional fluid lubrication in the bearings on geomagnetic oil, it is easy to generate boundary lubrication and solid contact friction, and the solid contact friction coefficient is bigger than boundary lubrication in order of magnitude. When bearing operation process of solid contact friction ratio increases, the temperature rise is faster[10]. Also it can be seen that the friction coefficient of oil bearing and the tendency of temperature rise, and the material of bearing has a lot to do.

Bearing material have shear strength and hardness. Along with the its decrease and increase, low shear strength is added in the base oil bearing and increases the hardness, also low shear strength is added in the $\mathrm{Cu}$ base oil of bearing graphite, all have the lower friction coefficient and temperature rise effect. And they don't add these elements compared to the sintering oil-retaining bearing, friction coefficient and the temperature rise obtain the very good inhibition. Master of oil bearing friction coefficient is determined by the operating characteristics and the relationship is between the bearing material, which are very important to develop oil bearing. 


\section{The INFLuence of COVER PIECES OF Blank SHEet SIZE AND PERFORMANCE}

The thickness of the blank is greater, the covering of parts is smaller, Fig. 1 is seen. The main material of covering parts size accuracy performance parameters is affected by the yield limit of sigma s plastic modulus, elastic modulus $\mathrm{E}$ and $\mathrm{E} 1$, hardening exponent $\mathrm{n}$, thick anisotropic coefficient $\mathrm{r}$, etc. The higher is material yield limit sigma s, the greater is the deformation of elastic recovery. The greater is the elastic modulus $\mathrm{E}$ and plastic modulus of E1, the smaller is the elastic recovery. The recovery of $\mathrm{N}$ value materials is smaller ,as shown in Fig. 2.

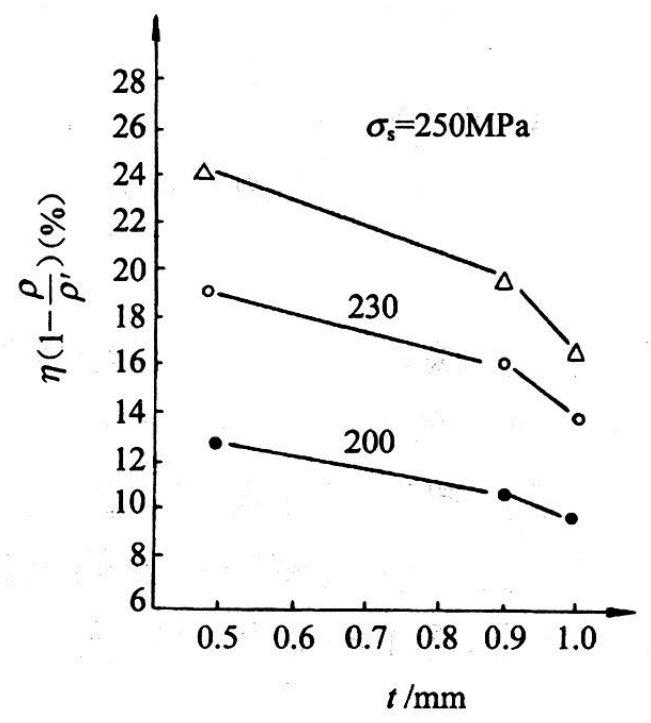

Figure 1. Influence of board deep to rebound

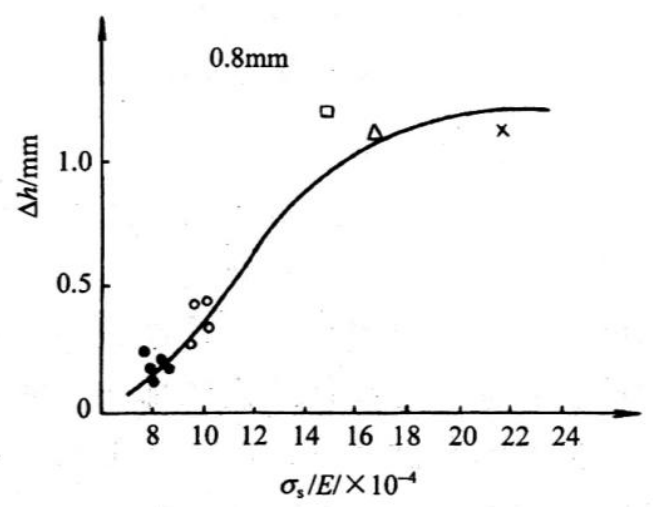

Figure 2. Influence of $\sigma \mathrm{s} / \mathrm{E}$ to rebound

Parts design module's main function is designed according to need of parts and components, the main process is to first draw sketch, then based on sketches generated entity, such as stretching, rotating, lofting, grooves, etc. Of course, it can work by modifying parts, including the fillet, chamfer, draft, thread and other operations. Assembly design module's main function is that designing a good parts is assembled to form components or assemblies. Aircraft sheet metal design module of main function is to design sheet metal parts, it can be for sheet metal parts for bending, flanging, subsidence and other operations, of course for general groove can be achieved. Fitting module's main function is to achieve the simulation movement of the parts or assemblies, last modified sequence, generate video. Skeleton skeleton is including bearings, channel steel, and turning the three parts of bearing, bearing selection of bearing, implementation framework of the bearing is divided into two kinds, which has two kinds of indexing plate bearings and plain bearing.

Block model is established in this paper. The following card board is as for example to establish three-dimensional model. Entering the part design module, it is drawing card board outline, function positioning because of card board is the outline drawing card board, and the surface of the workpiece contacting silhouette can use copy and paste function, the shape of the workpiece copy make sure card board closing to the workpiece [8]. Clicking the exit workbench is to click on the convex of contour. Choosing the card board on the surface is to click on the sketch workbench, and mobile card board slot rough sketches. Clicking on the groove processing is to select groove type until the next. The cursor is to the components geometry on the tree, click the right mouse button, to select properties, choose the color in the pop-up dialog box, to the color card board. This card board model is established in this paper. Main locations are positioned in the frame assembly jig support, butterfly nut positioning, clamping piece are mainly folding dynamic spiral compression device, folding the spiral compression device, folding move fork clamping device.

Skeleton frame assembly jig mainly adopt the method of welding and cutting according to the needs of the design of the frame size, and then welded into the skeleton, the welded frame is needed to be annealed or natural aging treatment, in order to eliminate the internal stress due to welding, preventing after deformation, and the skeleton requirement is for welding of flatness. Card board and the skeleton are mounted between block, block can be welded on the frame, it will be within the card board, which is fixed by bolts on the block, so that the card board installed. To install under the outer frame edge web frame, therefore it requires a wild card board within the relatively lower position of card board.

Compared various mold material coefficient of thermal expansion, the thermal expansion coefficient of silicone rubber is much greater than the ductile cast iron, that is to say, in the silicone rubber SMARTM process, thermal expansion deformation can be ignored in rigid female die and male die core nodular cast iron material. Based on the characteristics of mold structure and silicone rubber thermal expansion, technology can get fiber reinforced the original thickness and module of preforming process clearance expansion, expansion is the soft mode before the diameter in front of the delta, soft mold is wall thickness and diameter expansion after the soft mode, the molding of composite connection is skirt diameter, after forming the thickness, the fiber reinforced composite material connection skirt products, 
after preforming body is compaction thickness silicone rubber soft mode expansion stroke.

Assembly type frame is composed of the following sections that frame and location, the type of substrate is used for fixed and support of the clamping and positioning bear weight of parts in the assembly process, and it can ensure the accuracy and stability of the spatial location of components, type rack main working components is used to ensure the work piece with accurate position in the assembly process, it is to make the work piece firmly down on the locations of strength element. Auxiliary equipment is including job pedal, ladder, bracket, workbench, hoisting hanging, trucks and lighting equipment. The assembling rack must have a higher position accuracy, if the location of the frame is errors, then the assembly good product must also have the error, the accuracy of location has a lot of, such as a ground level degree, skeleton frame of manufacturing accuracy and so on. The assembly jig design can improve the work efficiency. The frame structure simplify, components should be standardized. Place state machine is in the frame of the box. Artifacts should make workers under the most favorable work attitude, it should make the most of the operation under the standing posture, within the scope of work, in addition, it also should consider to save workshop area, after comprehensive consideration for box in the placement of assembly type rack status should be used positioning clamping in horizontal, when assembling, it can rotate according to specific circumstances, for the workers in the best working state.

\section{CONCLUSIONS}

Under the condition of low pressure, high speed, oil bearing and fluid lubricated bearing and geomagnetic oil supply, it is smaller friction coefficient compared to conventional bearing, under the condition of high pressure and low speed, oil leakage phenomenon is serious, the oil film is thinning, added in the region of the fluid lubrication boundary, the friction coefficient is rising sharply in lubrication and solid contact friction.

Oil bearing lubricating were found in the pore of bearing body, so it is even more than the critical point, compared with the conventional bearing, the friction coefficient is rising also quite gentle, not prone to burn phenomenon. When the load increases to $0.6 \mathrm{MPa}$ above, friction coefficient rises, which is connected porosity high oil bearing, it starts to increase with temperature. When the load increases more than 1.0 MPa, porosity lower oil bearing also increases with temperature, and friction coefficient rises, the friction coefficient and the temperature rise are of the value of the load pressure increase, as the speed increases when it is moving to the low voltage side.

The oil pressure is the slip plane with the easy leakage, on the friction of fluid, lubrication adds boundary lubrication, and solid contact is mixed friction state of geomagnetic oil supply of conventional bearing. So oil bearing can be used for calculation of the coefficient friction, the conventional bearing calculation is by formula of the coefficient friction.

\section{REFERENCES}

[1] Zhao jun, Conical workpiece deep system in intelligent material parameters and the friction coefficient of on-line identification, Beijing: plastic engineering journal, pp.48-50, 2001.

[2] Zhao ZhenDuo, The friction and lubrication of metal plastic forming technology, Beijing: chemical industry press, pp. 50-53, 2004.

[3] WenWeiDong, Prediction model based on the fuzzy reliability, aircraft engine ,pp. 322-323, 2004.

[4] Middleman S, An introduction to fluid dynamics ,John Wiley and Sons Inc, New York, pp.16-17,1998.

[5] Liu ZhanJun,Difficulty reliability prediction research of titanium plate stamping forming based on the fuzzy control, plastic engineering journal, Beijing, pp. 63-66,2005.

[6] Feng Jing , The Mixture of The Multimode System Reliability Growth Model,Computer Application Research Supplement, pp.6061, 2003

[7] Xu Yuxiu, Complex Mechanical Fault Diagnosis Method of Fractal and Wavelet, Mechanical Industry Publishing House,Beijing, pp.2425,2005.

[8] Weng chaoxi, Reliability Growth, Science Press, Beijing, pp.130131,1993 .

[9] Guo Fang, Reliability Data Collection And Analysis, National Defence Industry Press, p22,1995.

[10] Wen WeiDong, Prediction model based on the fuzzy reliability, aircraft engine, Beijing, pp.322-323,2003. 